\title{
Rapid Eye Movement (REM) sleep: cholinergic mechanisms ${ }^{1}$
}

Otto Loewe conceived of the experiment that led to the discovery of Vagusstoff or acetylcholine during a dream. As this review will attempt to show, it is likely that acetylcholine, acting as a neurotransmitter on a muscarinic synapse within the dorsal tegmentum of the pons, triggered the dream that resulted in its own discovery.

Evidence for the involvement of acetylcholine with Rapid Eye Movement (REM) sleep comes both from human and animal studies. REM sleep is a complicated state, involving, on the psychological level, dreaming, and, on the physiological, activation of the EEG, bursts of rapid eye movements, atonia of the major antigravity muscles, monophasic waves in the pontine, geniculate and occipital areas (PGO spikes), hippocampal theta waves, variability of autonomic functioning, and increased firing rates of most central neurones (with notable exceptions, to be mentioned later). There is also a circadian propensity to REM sleep in man and many mammals. Acetylcholine may be involved in nearly all aspects of REM sleep.

\section{ANIMAL STUDIES}

Six different types of data from animal studies suggest that acetylcholine plays an important role in REM sleep.

\section{Spontaneous release of acetylcholine}

Concentrations of acetylcholine are increased during REM sleep compared with NREM sleep in a cortical cup in the cat (Jasper \& Tessier, 1971), in the effluent of the push-pull cannulae in the striatum (Gadea-Ciria et al. 1973), and in the ventricles of the dog (Haranth \& Venkatakrishna-Bhatt, 1973).

\section{Administration of a synthesis inhibitor}

Both Hazra (1970) and Domino \& Stawiski (1970) found less REM sleep following the administration of hemicholinium, which reduces synthesis of acetylcholine by blocking uptake of choline, the biosynthetic precursor.

\section{Administration of pharmacological agonists}

Direct application of cholinergic agonists to specific brainstem sites elicits REM or REM-like states. This is true of drugs with mixed muscarinic-nicotinic properties, such as carbachol (George et al. 1964; Baxter, 1969; Mitler \& Dement, 1974; Van Dongen et al. 1978; Velasco et al. 1981; Hobson, 1982), relatively pure muscarinic agonists, such as oxotremorine (George et al. 1964), bethanacol, or cis-methyl-diaxolane (Hobson, 1982), and acetylcholine itself (Hernandez-Peon et al. 1963; Hobson, 1982). The anatomical site is crucial to the physiological state produced. The anterior dorsal pons, such as the fastigial tegmental gigantocellular (FTG) group of cells, has been among the best for eliciting REM-like states, the sublocus coeruleus for inducing atonia, and the posteroventral pontine formation for the evocation of stereotyped eye movements (McGinty \& Drucker-Colin, 1982; Hobson, 1982). In some instances, the state produced by cholinergic agonists appears completely normal, except that its duration is prolonged (Hobson, 1982). Interestingly, however, the administration of cholinergic agonists has inhibited REM sleep when given in medulla, midbrain,

\footnotetext{
1 Address for correspondence: Professor J. Christian Gillin, Department of Psychiatry - M003, University of California at San Diego, San Diego, Ca 92093, USA. Address for Dr N. Sitaram: Lafayette Clinic, Wayne State University, Detroit, Michigan, USA.
} 
or locus coeruleus (George et al. 1964; Masserano \& King, 1982; Hobson, 1982; Van Dongen et al. 1978). These observations are consistent with the reciprocal interaction model for the control of REM and NREM sleep, which is discussed below (Hobson et al. 1976).

\section{Administration of cholinesterase inhibitors}

Systematically given physostigmine produces prolonged REM periods (Jouvet, 1975) and rapid eye movements, PGO spikes, loss of muscle rigidity, and enhanced firing rates of FTG cells (Pompeiano, 1980 ) in cats transected at precollicular or retrocollicular levels. Domino et al. (1968) induced REM-like states in intact cats with physostigmine and arecoline, a muscarinic agonist. Furthermore, on the basis of studies in reserpinized animals, Karczmar et al. (1970) found that physostigmine induced REM sleep and proposed that REM sleep is facilitated as the ratio of cholinergic to aminergic activity increases.

\section{Administration of cholinergic antagonists}

Atropine and scopolamine delay and reduce the amount of REM sleep in intact and pontine animals (Jouvet, 1975; Domino et al. 1968), diminish the number of PGO spikes (Henrickson et al. 1972), and block the REM promoting effects of cholinergic agonists and cholinesterase inhibitors (George et al. 1964; Domino et al. 1968; Jouvet, 1975; Pompeiano, 1980; Hobson, 1982).

\section{Electrophysiological and neurophysiological studies}

A number of neurones within pontine tegmentum (such as FTG) markedly increase their firing rates during REM sleep (the so-called REM-on cells) and are presumably cholinoreceptive and cholinomimetic (Pompeiano, 1980; Hobson et al. 1976; McGinty \& Drucker-Colin, 1982). In addition, there are cells which slow their rate or cease firing during REM sleep (the so-called REM-off cells), particularly in dorsal raphe, portions of locus coeruleus, and reticular formation (McGinty \& Drucker-Colin, 1982; Pompeiano, 1980; Sakai, 1980; Hobson, 1982). There is no agreement, however, that either of these cell groups or any others are necessary for REM sleep (Jones et al. 1977; Sastre et al. 1979). Nevertheless, it has been proposed that the cholinergic on-cells and the aminergic off-cells mutually interact: the former are excitatory to themselves and the latter cells; the latter are inhibitory to themselves and to the former (Hobson et al. 1976). A mathematical model has been proposed by Hobson et al. (1976), based upon the Lotka-Volterra equations, to relate the time course and rate of timing of 'on' and 'off' cells and to account for the oscillation between REM and NREM sleep.

\section{HUMAN CHOLINERGIC STUDIES}

Evidence for the cholinergic involvement of REM sleep in man comes from pharmacological studies utilizing receptor blocking agents, cholinesterase inhibitors, and muscarinic agonists. In early studies Toyoda $e t$ al. (1966) showed that atropine and scopolamine delayed and reduced REM sleep in man. In addition, Sagales $e t$ al. (1975) showed that tolerance to these REM suppressive effects developed within three consecutive nightly doses of scopolamine.

On the other hand, both physostigmine and arecoline induced REM sleep when administered intravenously to sleeping normal volunteers during either the first or second NREM period (Sitaram \& Gillin, 1980). The effects of physostigmine, however, were both time and dose dependent. At lower doses, REM -sleep iwas elicited; at higher doses, wakefulness. The REM periods induced by physostigmine and arecoline were entirely normal in their physiological appearance (EEG, eye movements, atonia, duration). Furthermore, the phenomenology of dreaming appeared completely normal: mental activity recalled from physostigmine induced REM periods was similar to that recalled following awakenings from spontaneous REM periods in terms of being 'dream-like', bizarre, and colourful. Spiegel (1984) has also supported the hypothesis that muscarinic stimulation induces REM sleep by administering RS 86 , an experimental muscarinic agonist which shortened REM latency and increased REM sleep in normal volunteers. 
As would be expected, scopolamine delayed REM sleep and blocked the REM inducing effects of arecoline (Sitaram \& Gillin, 1980). Moreover, the tolerance which Sagales et al. (1975) found with three consecutive doses of scopolamine at bedtime may involve the development of muscarinic supersensitivity. To test this hypothesis, scopolamine was administered for three consecutive mornings; by the third night, REM latency (the elapsed time from sleep onset to the first REM period) fell significantly; by the second night of pre-treatment with scopolamine each morning, the REM inducing effects of arecoline were potentiated, which is also consistent with the hypothesis that REM initiation involves a muscarinic synapse and that tolerance to scopolamine may involve muscarinic supersensitivity.

\section{IMPLICATIONS AND APPLICATIONS}

\section{Psychiatric conditions with short REM latency}

Short REM latency (the time between the onset of sleep and the first REM period) has been well documented in patients with major depressive disorders (Kupfer, 1976; Gillin, 1982). It has also been observed in some patients with acute and chronic schizophrenia (Stern et al. 1969; Jus et al. 1973), anorexia nervosa (Neil et al. 1980), obsessive-compulsive disorders (Rapoport et al. 1981; Insel et al. 1982), and pain syndromes (Blumer et al. 1982).

Because short REM latency has been studied so extensively in depression, the following discussion will focus on this aspect. Assuming that REM latency is inversely related to the ratio of cholinergic to monoaminergic activity (see above discussion), then the short REM latency of depression might be consistent with the cholinergic-noradrenergic balance hypothesis of affective disorders originally proposed by Janowsky et al. (1972). Direct evidence is lacking for this interpretation of the sleep disturbance of depression, but the following observations are pertinent. First, the sleep changes following the morning administration of scopolamine for three days, described above (Sitaram \& Gillin, 1980), mimic those seen in major depression (Gillin et al. 1979) - i.e. short REM latency, increased REM density, reduced total sleep time and sleep efficiency. Secondly, patients with major affective illness appear to be unusually sensitive to the REM-inducing effects of arecoline. This has been demonstrated by a technique we have called the Cholinergic REM Induction Test (CRIT) (Sitaram et al. 1980, 1982). In this test the elapsed time until the onset of the second REM period is measured, following an infusion of either placebo or arecoline, given 25 minutes following the first REM period. The latency was significantly more rapid after arecoline than after placebo in both depressed patients and controls, but the response was considerably longer in controls than in remitted bipolar patients, patients with anorexia nervosa who were or had been depressed compared with those who were not, patients hospitalized with depression, and in a small number of subjects who presented themselves as normal but who were found to have had a past episode suggestive of depression. Response on the CRIT also appears to be concordant in identical twins (Nurnberger et al. 1983). Recently, Berger \& Lund (1982) found compatible results, using a modification of the CRIT. Infusing physostigmine $(0.5 \mathrm{mg}) 5$ minutes after sleep onset, they found more awakening in depressives than controls, suggesting an enhanced responsiveness in depressives to cholinergic stimulation. All these findings suggest that the CRIT may be measuring a genetically influenced trait marker for depression. It is possible that depression is associated with a trait-related muscarinic supersensitivity and a state-related aminergic deficiency.

Another application of these concepts and methods might be in the syndromes associated with antidepressant withdrawal, which Dilsaver et al. (1983) postulate to be a state of 'cholinergic overdrive'. Not only are depressive symptoms likely to be exacerbated during this period, but levels of REM sleep are high (Gillin, 1982).

\section{Narcolepsy}

Since short REM latency is a significant feature of narcolepsy, it is not surprising that physostigmine and arecoline precipitate cataplexy (muscle atonia probably related to that seen in REM sleep) in narcoleptic dogs (Delashaw et al. 1979). These observations are also consistent with recent findings 
of increased numbers of muscarinic receptors in brains from narcoleptic dogs (Boehme et al. 1982). Attempts to treat a small number of narcoleptic patients with the anticholinergic drug, trihexyphenidyl, which has potent anticholinergic effects, or to induce narcoleptic symptoms with physostigmine, were unsuccessful but not definitive (Gillin et al. 1976).

\section{Mechanism of action of antidepressants}

Since the antidepressants, with few exceptions, delay the onset of and reduce the amount of REM sleep, it is interesting that both Khazan et al. (1967) and Hill et al. (1979) showed that physostigmine reversed these REM suppressive effects in animals. This technique provides a functional method for studying the mechanism of action of antidepressants. Preliminary attempts have been made to study physostigmine's effect upon REM sleep in a new antidepressant in man (Ferini-Strambi et al. 1983).

\section{Myasthenia gravis}

Disturbance of cholinergic, nicotinic neuromuscular transmission is thought to underlie the peripheral clinical manifestations of this disease. Central manifestations have also been postulated. Two groups have tried to use EEG sleep studies of the amount and timing of REM sleep to demonstrate central cholinergic abnormalities, but their results have apparently been discrepant. The first, by Papazian (1976), reported decreased and disturbed REM sleep. The second, by Mennuni et al. (1983), found decreased REM latency. Further studies are needed to clarify these differing results.

\section{Sleep and memory}

It has long been hypothesized that REM sleep plays an important role in the consolidation and reorganization of memory. Furthermore, cholinergic mechanisms are also implicated in memory. Studies which tie together these concepts may be of value. On the clinical side, REM sleep is diminished in some children with mental retardation (Castaldo, 1967) and in some patients with Alzheimer's Dementia (Feinberg et al. 1967), and it would be interesting to correlate cholinergic deficits and REM sleep in these patients.

\section{Poisoning with anticholinesterase agents}

In an experimental study of the effects of long-acting cholinesterase inhibitors in volunteers, Bowers et al. (1964) reported excessive nightmares and dreaming. Although sleep studies were not performed in that study, Stoyva \& Metcalf (1968) observed increased amounts and early onset of REM sleep in farmers exposed to anticholinesterase insecticides.

\section{Chronobiology}

A number of interesting theoretical models of sleep-wake control mechanisms have recently been proposed (Kronauer et al. 1982; Borbeley, 1982). Little is known about the biochemistry or neuropharmacology of circadian systems, but acetylcholine might be involved. Circadian rhythms for muscarinic receptors have been described in autopsy material from human cortex (Perry et al. 1977) and from rat brain (Kafka et al. 1981). Moreover, Kronauer et al. (1982) propose the existence of a 'strong oscillator', termed the 'X oscillator', which regulates the circadian organization of REM sleep, temperature, and cortisol. Since cholinergic agonists lower body temperature and stimulate cortisol secretion, one wonders whether acetylcholine acts upon or through the ' $\mathrm{X}$ oscillator'. Zatz \& Brownstein (1979) have shown that carbachol administration mimics the effect of light in the rat - i.e. it can phase advance or delay melatonin rhythms, depending upon the circadian phase of administration. This effect, however, appears to be nicotinic rather than muscarinic.

Sitaram \& Gillin (1980) have also shown that the ultradian REM-to-REM rhythm in man can be lengthened and shortened by the intravenous administration of scopolamine and arecoline or physostigmine between REM periods, respectively. 


\section{DISCUSSION}

This review has deliberately emphasized the diverse role of acetylcholine in REM sleep, but is not intended to imply that acetylcholine is the only neurotransmitter involved with REM sleep. In some ways, however, its role is better established than that of other neurotransmitters, such as serotonin and norepinephrine, which may not even be essential to the occurrence of REM sleep. On the other hand, techniques for selective lesioning and mapping of cholinergic neurones in brain have been unavailable until recently and have not been used extensively in sleep studies. Cholinergic neurones are widely distributed throughout the brain, and further studies will be needed to establish whether acetylcholine plays an essential or a modulatory role and how and where it interacts with other neurochemical systems in the physiology of sleep. Then the role of cholinergic mechanisms in both normal and pathological REM sleep may become clearer.

\section{REFERENCES}

Baxter, B. L. (1969). Induction of both emotional behavior and a novel form of REM sleep by chemical stimulation applied to cat mesencephalon. Experimental Neurology 23, 220-229.

Berger, M. \& Lund, R. (1982). The influence of physostigmine on REM sleep in neurotic and endogenous depressed patients. Sixth European Congress of Sleep Research, Zurich, 23-26 March.

Blumer, D., Zorich, F., Heilbronn, M. \& Roth, T. (1982). Biological markers for depression in chronic pain. Journal of Nervous and Mental Disease 170, 425-428.

Boehme, R., Baker, T. L., Mefford, I. M., Ciarenello, R. \& Dement, W. C. (1982). Muscarinic cholinergic receptor abnormalities in canine narcolepsy. Sleep Research 11, 45.

Borbely, A. (1982). A two process model of sleep regulation. Human Neurobiology 1, 195-205.

Bowers, M. B., Goodman, E. \& Sim, V. M. (1964). Some behavioral changes in man following anticholinesterase administration. Journal of Nervous and Mental Disease 138, 383-389.

Castaldo, V. (1969). Down's syndrome: a study of sleep patterns related to level of mental retardation. American Journal of Mental Deficiency 74, 187-190.

Delashaw, J. B., Foutz, A. S., Guilleminault, C. \& Dement, W. C. (1979). Cholinergic mechanisms and cataplexy in dogs. Experimental Neurology 66, 745-757.

Dilsaver, S. C., Kronfol, Z. \& Sackellares, J. C. (1983). Antidepressant withdrawal syndromes: evidence supporting the cholinergic overdrive hypothesis. Journal of Clinical Psychopharmacology 3, 157-164.

Domino, E. F. \& Stawiski, M. (1970). Effect of cholinergic antisynthesis agent HC-3 on the awake-sleep cycle of the cat. Psychophysiology 7, 315-316.

Domino, E. F., Yamamoto, K. \& Dren, A. T. (1968). Role of cholinergic mechanisms in states of wakefulness and sleep. In Anticholinergic Drugs and Brain Function in Animals and Man (ed. P. B. Bradley and M. Fink), pp. 113-133. Progress in Brain Research, Vol. 28. Elsevier: Amsterdam.

Feinberg, I., Kresko, R. L. \& Heller, N. (1967). EEG sleep patterns as a function of normal and pathological aging in man. Journal of Psychiatric Research 5, 107-144.

Ferini-Strambi, L., Mariani, E., Minicucci, F., Mastrangelo, M., Medagliani, S. Binirani, S. (1983). REM facilitating activity of physostigmine in healthy subjects: antagonist effect of minaprine. APSS Meeting, Bologna, 18-22 July.

Gadea-Ciria, M., Stadler, H., Lloyd, K. \& Bartholini, G. (1973). Acetylcholine release within cat striatum during sleep-wakefulness cycle. Nature 243, 518-519.

George, R., Haslett, W. L. \& Jenden, D. J. (1974). A cholinergic mechanism in the brain stem reticular formation: induction of paradoxical sleep. International Journal of Neuropharmacology 3, 541-552.
Gillin, J. C. (1982). Sleep studies in affective illness: diagnostic, therapeutic, and pathophysiological implications. Psychiatric Annals 13, 367-384.

Gillin, J. C., Horwitz, D. \& Wyatt, R. J. (1976). Pharmacologic studies of narcolepsy involving serotonin, acetylcholine, and monoamine oxidase. In Advances in Sleep Research: Narcolepsy, pp. 585-603. Spectrum Publications: New York.

Gillin, J. C., Sitaram, N. \& Duncan, W. C. (1979). Muscarinic supersensitivity: a possible model for the sleep disturbance of depression. Psychiatric Research 1, 17-22.

Hanranth, P. S. R. K. \& Ventkatakrishna-Bhatt, H. (1973). Release of acetylcholine from perfused ventricles in unanaesthetized dogs during waking and sleep. Japanese Journal of Physiology 23, 241-248.

Hazra, J. (1970). Effect of hemicholinium-3 on slow wave and paradoxical sleep of cat. European Journal of Pharmacology 11, 395-397.

Henrikson, S. J., Jacobs, B. L. \& Dement, W. C. (1972). Dependence of REM sleep PGO waves on cholinergic mechanisms. Brain Research 48, 412-416.

Hernandez-Peon, R., Chavez-Jbana, G., Morgane, P. J. \& Timo-Iaria, C. (1963). Limbic cholinergic pathways involved in sleep and emotional behavior. Experimental Neurology 8, 93-111.

Hill, S., Reyes, R. \& Kupfer, D. J. (1979). Physostigmine induction of REM sleep in imipramine treated rats. Communications in Psychopharmacology 3, 261-266.

Hobson, J. A. (1982). How does the cortex know when to do what? A neurobiological theory of state control. Neuroscience Symposium Cerebral Cortex, Salk Institute, La Jolla, CA, 3-8 October.

Hobson, J. A., McCarley, R. W. \& McKenna, T. M. (1976). Cellular evidence bearing on the pontine brainstem hypothesis of desynchronized sleep control. In Neuronal Activity During the Sleep-waking Cycle (ed. M. Steriade and M. Hobson), pp. 279-376. Progress in Neurobiology, Vol. 6.

Insel, T. R., Gillin, J. C., Moore, A., Mendelson, W. B., Loewenstein, R. S. \& Murphy, D. L. (1982). The sleep of obsessive-compulsive patients. Archives of General Psychiatry 39, 1372-1377.

Janowsky, D. L., El-Yousef, M. K. \& Davis, J. M. (1972). A cholinergic-adrenergic hypothesis of mania and depression. Lancet ii, 632-635.

Jasper, H. \& Tessier, J. (1971). Acetylcholine liberation from cerebral cortex during paradoxical sleep. Science 172, 601-602.

Jones, B. E., Harper, S. T. \& Halaris, A. E. (1977). Effect of locus coeruleus lesions upon cerebral monoamine content, sleepwakefulness states, and response to amphetamine in the cat. Brain Research 124, 473-496.

Jouvet, M. (1976). Cholinergic mechanisms and sleep. In Cholinergic Mechanisms (ed. P. Waser), pp. 455-476. Raven Press: New York

Jus, K., Bouchard, M., Jus, A. K., Villeneuve, A. \& Lachance, R. (1973). Sleep EEG studies in untreated, long term schizophrenic patients. Archives of General Psychiatry 29, 386-390. 
Kafka, M. S., Wirz-Justice, A. \& Wehr, T. A. (1981). Circadian acetylcholine receptor rhythm in rat brain and its modification by imipramine. Neuropharmacology 20, 421-425.

Karczmar, A. G., Longo, V. G. \& Scoll de Caroll, S. (1970). A pharmacological model of paradoxical sleep: the role of cholinergic and monoamine systems. Physiology and Behaviour 5, 175-182.

Khazan, N., Bar, R. \& Sulman, F. G. (1967). The effect of cholinergic drugs on paradoxical sleep in the rat. International Journal of Neuropharmacology 6, 279-282.

Kronauer, R. E., Czeisler, C. A., Pilato, S. F., Moore-Ede, M. C. \& Weitzman, E. D. (1982). Mathematical model of human circadian system with two interacting oscillators. American Journal of Physiology 242, R3-R17.

Kupfer, D. J. (1976). REM latency: a psychobiological value for primary depressive disease. Biological Psychiatry 11, 159-174.

Masserano, J. M. \& King, C. (1982). Effects on sleep of acetylcholine perfusion of the locus coeruleus of cats. Neuropharmacology 27, 1163-1167.

McGinty, D. J. \& Drucker-Colin, R. R. (1982). Sleep mechanisms: biology and control of REM sleep. International Review of Neurobiology 23, 391-436.

Mennuni, G., Morante, M. T., Scoppetta, C. \& Bergonzi, P. (1983). Night sleep organization in myasthenic patients not undergoing therapy. Fourth International Congress of Sleep Research, Bologna, 18-22. July.

Mitler, M. M. \& Dement, W. C. (1974). Cataleptic-like behaviour in cats after microinjection of carbachol in pontine reticular formation. Brain Research 68, 335-343.

Neil, J. G., Merikanges, J. R., Foster, P. G., Merikanges, K. R., Spiker, D. G. \& Kupfer, D. J. (1980). Waking and all night sleep EEGs in anorexia nervosa. Clinical Electroencephalography 11, 9-15.

Nurnberger, J. I., Sitaram, N., Gershon, E. S. \& Gillin, J. C. (1983). A twin study of cholinergic REM induction. Biological Psychiatry. (In the press.)

Papazian, D. (1976). Rapid eye movement sleep alterations in myasthenia gravis. Neurology 26, 311-316.

Perry, E. K., Perry, R. H. \& Tomlinson, B. E. (1977). Circadian variations in cholinergic enzymes and muscarinic receptor binding in human cerebral cortex. Neuroscience 4, 185-189.

Pompeiano, O. (1980). Cholinergic activation of reticular and vestibular mechanisms controlling posture and eye movements In The Reticular Formation Revisited (ed. J. A. Hobson and M. A. B. Brazier), pp. 473-513. Raven Press: New York.

Rapoport, J., Elkins, R., Langer, D. H., Sceery, W., Buchsbaum, M. S., Gillin, J. C., Murphy, D. L., Zahn, T. P., Lake, R. Mendelson, W. B. \& Ludlow, C. (1981). Childhood obsessivecompulsive disorder. American Journal of Psychiatry 138, 1545-1555.
Sagales, T., Erill, S. \& Domino, E. F. (1975). Effects of repeated doses of scopolamine on the electroencephalographic stages of sleep in normal volunteers. Clinical Pharmacology and Therapeutics 18, 727-732.

Sakai, K. (1980). Some anatomical and physiological properties of ponto-mesencephalic tegmental neurons with special reference to the PGO waves and postural atonia during paradoxical sleep in the cat. In The Reticular Formation Revisited (ed. J. A. Hobson and M. A. B. Brazier), pp. 427-447. Raven Press: New York.

Sastre, J. P., Sakai, K. \& Jouvet, M. (1979). Persistance du sommeil paradoxica chez le chat après destruction de l'aire gigantocellulaire du tegmentum pontine par l'acide kainiane. Comptes rendus, Académie des sciences, Paris 289, 959-964.

Sitaram, N. \& Gillin, J.C. (1980). Development and use of pharmacological probes of the CNS in man : evidence of cholinergic abnormalities in primary affective illness. Biological Psychiatry 15, 925-955.

Sitaram, N., Nurnberger, J. I., Gershon, E. S. \& Gillin, J. C. (1980). Faster cholinergic REM sleep induction in euthymic patients with primary affective illness. Science 208, 200-202.

Sitaram, N., Nurnberger, J. I., Gershon, E. S. \& Gillin, J. C. (1982). Cholinergic regulation of mood and REM sleep: a potential model and marker for vulnerability to depression. American Journal of Psychiarry 139, 571-576.

Spiegel, R. (1984). Effects of RS 86, an orally active cholinergic agonist, on sleep in man. Psychiatric Research (in the press).

Stern, M., Fram, D., Wyatt, R. J., Grispoon, L. \& Tursky, B. (1969). All night sleep studies of acute schizophrenics. Archives of General Psychiatry 20, 470-477.

Stoyva, J. \& Metcalf, D. (1968). Sleep patterns following chronic exposure to cholinesterase inhibiting organophosphate compounds. Psychophysiology 5, 206.

Toyoda, J., Sakiu, K. \& Kuriharo, K. (1966). A polygraphic study of the effect of atropine on human nocturnal sleep. Folia Psychiatrica et Neurologica Japonica 120, 275-289.

Usin, S. \& Iwahara, S. (1977). Effects of atropine upon hypocampal electrical activity in rats with special reference to paradoxical sleep. Electroencephalography and Clinical Neurophysiology 42, 510-517.

Van Dongen, P. A., Brockamp, L. E. \& Cools, A. R. (1978). Atonia after carbachol microinjections near the locus cocruleus in cats. Pharmacology, Biochemistry and Behaviour 8, 527-532.

Velasco, M., Velasco, F., Romo, R. \& Estrada-Villanueva, F. (1981) Carbachol 'push-pull' perfusion in the reticular formation: effect on the contiguous multiple unit activity and other sleep-waking parameters in cats. Experimental Neurology 72, 318-331.

Zatz, M. \& Brownstein, M. J. (1979). Intraventricular carbachol mimics the effects of light on the circadian rhythm in the rat pineal gland. Science 203, 358-361. 